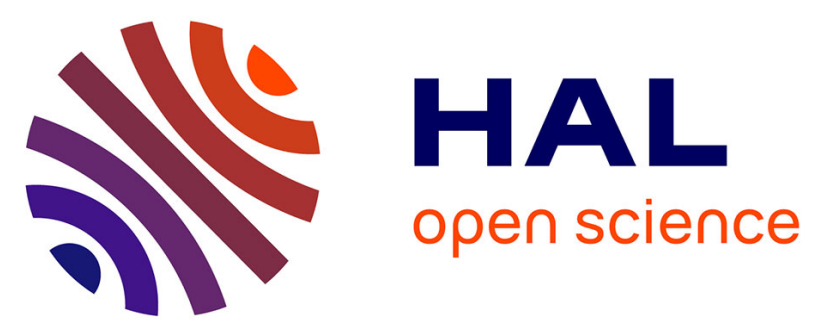

\title{
ADP-ribose polymer depletion leads to nuclear Ctcf re-localization and chromatin rearrangement(1).
}

Tiziana Guastafierro, Angela Catizone, Roberta Calabrese, Michele Zampieri, Oliviano Martella, Maria Giulia Bacalini, Anna Reale, Maria Di Girolamo, Margherita Miccheli, Dawn Farrar, et al.

\section{To cite this version:}

Tiziana Guastafierro, Angela Catizone, Roberta Calabrese, Michele Zampieri, Oliviano Martella, et al.. ADP-ribose polymer depletion leads to nuclear Ctcf re-localization and chromatin rearrangement(1).. Biochemical Journal, 2013, 449 (3), pp.623-30. 10.1042/BJ20121429 . pasteur-01053368

\section{HAL Id: pasteur-01053368 https://hal-riip.archives-ouvertes.fr/pasteur-01053368}

Submitted on 30 Jul 2014

HAL is a multi-disciplinary open access archive for the deposit and dissemination of scientific research documents, whether they are published or not. The documents may come from teaching and research institutions in France or abroad, or from public or private research centers.
L'archive ouverte pluridisciplinaire HAL, est destinée au dépôt et à la diffusion de documents scientifiques de niveau recherche, publiés ou non, émanant des établissements d'enseignement et de recherche français ou étrangers, des laboratoires publics ou privés. 


\title{
ADP-ribose polymer depletion leads to nuclear Ctcf re-localization and chromatin rearrangement ${ }^{1}$
}

\author{
Tiziana GUASTAFIERRO ${ }^{*} \dagger^{2}$, Angela CATIZONE $\dagger^{2}$, Roberta CALABRESE* $\uparrow$, Michele ZAMPIERI ${ }^{*} \uparrow$, Oliviano MARTELLA $\S$, \\ Maria Giulia BACALINI* $\uparrow$, Anna REALE* $\uparrow$, Maria DI GIROLAMO $\S$, Margherita MICCHELI*, Dawn FARRAR $\|$, Elena KLENOVA $\|$, \\ Fabio CICCARONE* $\dagger^{3}$ and Paola CAIAFA* $\dagger^{3}$ \\ *Department of Cellular Biotechnologies and Haematology "Sapienza" University Rome, V.le Regina Elena 324, 00161 Rome, Italy, †Pasteur Institute-Fondazione Cenci Bolognetti, P.le \\ A. Moro 5, 00185 Rome, Italy, łDepartment of Anatomy, Histology, Forensic Medicine and Orthopedics, Section of Histology and Embryology, Faculty of Pharmacy and Medicine, \\ "Sapienza" University Rome, V.le Regina Elena 324, 00161 Rome, Italy, §Consorzio Mario Negri Sud, Via Nazionale 8/A, 66030 Santa Maria Imbaro, Chieti, Italy, and ॥Department of \\ Biological Sciences, University of Essex, Wivenhoe Park, Colchester, Essex C04 3SQ, U.K.
}

Ctcf (CCCTC-binding factor) directly induces Parp [poly(ADPribose) polymerase] 1 activity and its PARylation [poly(ADPribosyl)ation] in the absence of DNA damage. Ctcf, in turn, is a substrate for this post-synthetic modification and as such it is covalently and non-covalently modified by PARs (ADP-ribose polymers). Moreover, PARylation is able to protect certain DNA regions bound by Ctcf from DNA methylation. We recently reported that de novo methylation of Ctcf target sequences due to overexpression of Parg [poly(ADP-ribose)glycohydrolase] induces loss of Ctcf binding. Considering this, we investigate to what extent PARP activity is able to affect nuclear distribution of Ctcf in the present study. Notably, Ctcf lost its diffuse nuclear localization following PAR (ADP-ribose polymer) depletion and accumulated at the periphery of the nucleus where it was linked with nuclear pore complex proteins remaining external to the perinuclear Lamin B1 ring. We demonstrated that PAR depletion-dependent perinuclear localization of Ctcf was due to its blockage from entering the nucleus. Besides Ctcf nuclear delocalization, the outcome of PAR depletion led to changes in chromatin architecture. Immunofluorescence analyses indicated DNA redistribution, a generalized genomic hypermethylation and an increase of inactive compared with active chromatin marks in Parg-overexpressing or Ctcf-silenced cells. Together these results underline the importance of the cross-talk between Parp1 and Ctcf in the maintenance of nuclear organization.

Key words: chromatin structure, CCCTC-binding factor (Ctcf), poly(ADP-ribose) glycohydrolase (Parg), poly(ADP-ribose) polymerase 1 (Parp1), poly(ADP-ribosyl)ation (PARylation).

\section{INTRODUCTION}

PARylation [poly(ADP-ribosyl)ation], a post-translational modification catalysed by enzymes of the PARP [poly(ADP-ribose) polymerase] family, leads to the covalent introduction of the ADPribose units on to acceptor proteins and also on to PARPs themselves [1]. Parg [poly(ADP-ribose) glycohydrolase] degrades PARs (ADP-ribose polymers), reversing the modification by its exo- and endo-glycosydase activities [2]. PARs, present on covalently PARylated proteins, are able to interact non-covalently with other proteins binding a 20 -amino-acid PAR-binding motif [3], as well as the PBZ (PAR-binding zinc finger) motif [4] and the well-characterized 'macro domain' [5]. Parp1 (also termed ARTD1 on the basis of recent nomenclature [6]) is the founder of the PARP family [1]; in its PARylated form Parp1 participates in emergency and housekeeping roles, being involved in DNA damage repair and in the control of gene expression respectively.

Parp1 also orchestrates genome organization by regulating genome-wide transcription [7] and epigenetic states of chromatin [8]. In the latter, Parp1 leads to chromatin decondensation, PARylating itself as well as core histones and the linker histone
H1, whereas the absence of PARylation induces chromatin condensation [8,9]. Chromatin condensation can be mediated by the histone macro2A variant, whose NHD (non-histone domain) recruits Parp1, inducing its inhibition [5,10]. Moreover, Parp1 activity is also involved in counteracting the ATPdependent nucleosome-remodelling factor ISWI [11] and in inhibiting enzymes involved in chromatin repression such as the histone demethylase KDM5B [9]. PARylation is also important for maintaining DNA methylation patterns of the genome. In fact, PARylated Parp1 and Dnmt1 (DNA methyltransferase 1) interact and PARs, present on Parp1 itself, bind non-covalently with Dnmt1 preventing its access to DNA and thus its DNA methyltransferase activity. As a consequence, PAR depletion, induced through the treatment of cells with a competitive inhibitor of PARP activity [12] or through ectopic overexpression of Parg [13], leads to the introduction of new anomalous methyl groups on to unmethylated DNA regions. Concerning genome regions, where the non-methylated state is necessary for their functions and the outcome of the process they control, the presence of PARs on them has been found to be important [13,1418]. The multifunctional Ctcf (CCCTC-binding factor) has been

Abbreviations used: CLSM, confocal laser-scanning microscopy; CRM1, chromosome region maintenance 1; Ctcf, CCCT-binding factor; DMR1, differentially methylated region 1; Dnmt1, DNA methyltransferase 1; EGFP, enhanced green fluorescent protein; ER, endoplasmic reticulum; LMB, leptomycin B; 5-MeCyt, DNA 5-methylcytosine; H3K4me2, histone H3 dimethylated at Lys ${ }^{4}$; H3K9me3, histone H3 trimethylated at Lys ${ }^{9}$; NPC, nuclear pore complex; PAR, ADP-ribose polymer; Parg, poly(ADP-ribose) glycohydrolase; PARP, poly(ADP-ribose) polymerase; PARylation, poly(ADP-ribosyl)ation; ROI, region of interest; siRNA, small interfering RNA; TRITC, tetramethylrhodamine $\beta$-isothiocyanate.

This paper is dedicated to the memory of our wonderful colleague and friend, Dr Maria Malanga, who recently passed away. Her bright mind and her calmness in dealing with any matter will be forever engraved in our hearts.

2 These authors contributed equally to this work.

3 Correspondence may be addressed to either of these authors (email ciccarone@bce.uniroma1.it or caiafa@bce.uniroma1.it). 
identified as an important player by which PARylation preserves the unmethylated state of some regulatory DNA sequences $[15,16,18]$. In fact, Ctcf by itself is able to activate PARylation of Parp1 even in the absence of DNA damage [19]. Moreover, Ctcf undergoes covalent [14] and non-covalent PARylation [18] and how Ctcf selects these modifications to perform its numerous functions remains to be defined.

The fact that Ctcf selectively binds non-methylated DNA sequences and that out of the numerous Ctcf-binding sites on the genome, many of them coincide with those of Parp1 [16], indicates that $\mathrm{Ctcf}$ can mark those regions that must be maintained as non-methylated in the genome. Maintaining of non-methylated states could be reached through the formation of a Ctcf-Parp1 complex, PARylation of Parp1 and, in turn, inhibition of Dnmt1 activity [19]. This mechanism has been indicated as the one involved in maintaining the non-methylated $p 16$ gene promoter $\mathrm{CpG}$ island [15] and in preserving the methylation profile of the DMR1 (differentially methylated region 1) at the $I g f 2 / H 19$ imprinted locus [18]. On the basis of the above, PARylated Parp1, following binding with Ctcf, would become an epigenetic mark of DNA regions that have to be maintained as non-methylated in the genome [20]. Considering that DNA hypermethylation dependent on PAR depletion induces the loss of Ctcf binding from DNA regions and that putative target sequences for Ctcf and Parp1 often overlap, the aim of this research is to verify whether Ctcf localization is influenced by PARs.

\section{EXPERIMENTAL}

\section{Subcellular fractionation and Western blot analysis}

Nuclear and cytosolic fractions were collected from trypsinized and PBS-washed cells by centrifugation following incubation (30 min) in isolation buffer containing $10 \mathrm{mM}$ Hepes, pH 7.9, $10 \mathrm{mM} \mathrm{KCl}, 1.5 \mathrm{mM} \mathrm{MgCl}{ }_{2}, 50 \mathrm{mM} \mathrm{NaF}, 0.5 \mathrm{mM}$ dithiothreitol and $0.3 \mathrm{mM}$ PMSF. The nuclear fraction was lysed in RIPA buffer $(50 \mathrm{mM}$ Tris/ $\mathrm{HCl}, \mathrm{pH} 8,150 \mathrm{mM} \mathrm{NaCl}, 0.5 \%$ sodium deoxycholate, $0.1 \%$ SDS, $1 \%$ Nonidet P40 and 1 mM EDTA). Both buffers were supplemented with protease inhibitors (Complete $^{\mathrm{TM}}$ EDTA-free, Roche Applied Science). Protein concentration was determined using the Bradford protein assay reagent (Bio-Rad Laboratories) using BSA (Promega) as a standard. Equal protein amounts were subjected to SDS/PAGE ( $8 \%$ gels) and blotted on to Hybond-ECL nitrocellulose membranes (Amersham Biosciences). The antibodies employed were as follows: mouse monoclonal anti-PAR antibody (10 HA, Trevigen), mouse monoclonal anti-Myc antibody (9E10 clone, hybridoma-conditioned medium) [13], mouse monoclonal anti-Parp1 antibody (C2-10, Alexis), rabbit polyclonal antiCtcf antibody (Millipore), goat polyclonal anti-Ctcf antibody (Santa Cruz Biotechnology), mouse monoclonal anti- $\alpha$-tubulin antibody (clone B-5-1-2, Sigma-Aldrich), rabbit polyclonal anti(lamin B1) antibody (AbCam), mouse monoclonal anti-NPC (nuclear pore complex) antibody (AbCam), donkey anti-goat, goat anti-mouse and anti-rabbit horseradish peroxidase-conjugated antibodies (Santa Cruz Biotechnology).

\section{Transfection of cells}

In transfection experiments $0.7 \times 10^{6}$ cells were seeded in $60 \mathrm{~mm} \times 15 \mathrm{~mm}$ culture dishes and transfected with Lipofectamine $^{\mathrm{TM}}$ Plus reagent (Invitrogen), following the manufacturer's protocol. Assays were performed with $4 \mu \mathrm{g} / \mathrm{dish}$ of purified plasmid DNA of either empty Myc-vector (pcs2) as the control or Myc-PARG construct (pcs2-Myc-PARG) [13] together with $0.4 \mu \mathrm{g} /$ dish of pBabe-puro (Addgene) vector for puromycin selection of transfected cells. After $24 \mathrm{~h}$, cells were incubated for a further $72 \mathrm{~h}$ in culture medium supplemented with puromycin (2.5 $\mu \mathrm{g} / \mathrm{ml}$, Calbiochem). In pcs2-Myc-PARG/EGFP (enhanced green fluorescent protein)-Ctcf or pcs2-Myc-PARG/EGFP-Ctcf mutated co-transfection experiments, $1.5 \times 10^{5}$ cells were seeded in a 35-mm-diameter $\mu$-Dish (ibidi $\mathrm{GmbH}$ ) and transfected with Lipofectamine ${ }^{\mathrm{TM}}$ Plus reagent (Invitrogen) adopting the manufacturer's protocol.

\section{Knockdown experiments}

In experiments with Ctcf, Parpl and Parp2 silencing, $0.16 \times 10^{6}$ cells were seeded in $60 \mathrm{~mm} \times 15 \mathrm{~mm}$ culture dishes and transfected for $48 \mathrm{~h}$ with siRNA (small interfering RNA) (Dharmacon) at a final concentration of $50 \mathrm{nM}$ using Lipofectamine $^{\mathrm{TM}} 2000$ reagent (Invitrogen) following the manufacturer's instructions.

\section{Co-immunoprecipitation}

Nuclear and cytosol fractions or total L929 cells were lysed in immunoprecipitation buffer $(50 \mathrm{mM}$ Tris/ $\mathrm{HCl}, \mathrm{pH} 7.5,5 \mathrm{mM}$ EDTA, $300 \mathrm{mM} \mathrm{NaCl}, 1 \%$ Nonidet P40 and $1 \%$ Triton X100) supplemented with protease inhibitors (Complete ${ }^{\mathrm{TM}}$ EDTAfree, Roche Applied Science). Lysates (1.5 mg) were pre-cleared with Protein A-agarose beads (Upstate) on a rotating shaker at $4{ }^{\circ} \mathrm{C}$ for $2.5 \mathrm{~h}$. Pre-cleared lysates were incubated with rabbit polyclonal anti-Ctcf antibody (Millipore) and with normal rabbit IgG (Santa Cruz Biotechnology) on a rotating shaker overnight at $4{ }^{\circ} \mathrm{C}$. The agarose beads, previously saturated with BSA $(1 \mu \mathrm{g} / \mu \mathrm{l})$ overnight, were added to the lysate/antibody solutions and incubated for $2 \mathrm{~h}$ on a rotating shaker at $4{ }^{\circ} \mathrm{C}$. Subsequently, beads were washed in immunoprecipitation buffer, then boiled in SDS/PAGE sample buffer, and the eluted proteins were analysed by Western blotting.

\section{Confocal and time-lapse video microscopy}

Cells were fixed in paraformaldehyde and permeabilized in $0.2 \%$ Triton X-100 in PBS supplemented with $0.5 \%$ BSA for $1 \mathrm{~h}$ at room temperature $\left(23^{\circ} \mathrm{C}\right)$. Cells were incubated with primary antibody, then washed in PBS and incubated with the secondary antibody. As regards 5-MeCyt (DNA 5-methylcytosine) staining, cells were permeabilized in PBS, $1 \%$ BSA and $0.5 \%$ Triton X-100 for $30 \mathrm{~min}$, then washed with PBS and treated with $4 \mathrm{M} \mathrm{HCl}$ for $30 \mathrm{~min}$ at $37^{\circ} \mathrm{C}$. Following extensive PBS washes, cells were blocked in PBS, $1 \%$ BSA and $0.1 \%$ Triton X-100 for $30 \mathrm{~min}$ and incubated with anti-5-MeCyt antibody at $4{ }^{\circ} \mathrm{C}$ overnight. The cells were then extensively washed and incubated for $1 \mathrm{~h}$ at room temperature with the secondary antibodies, and then treated with RNase A $(1 \mathrm{mg} / \mathrm{ml})$ for $30 \mathrm{~min}$.

The antibodies employed were the same used in Western blot experiments. Other antibodies used were: rabbit polyclonal antinucleophosmin/B23 antibody (AbCam), mouse monoclonal anti5-MeCyt antibody (Eurogentec), rabbit polyclonal anti-H3K4me2 (histone $\mathrm{H} 3$ dimethylated at $\mathrm{Lys}^{4}$ ) antibody (Millipore) and rabbit polyclonal anti-H3K9me3 (histone $\mathrm{H} 3$ trimethylated at Lys $^{9}$ ) antibody (Millipore). Cells were stained with TO-PRO-3 (Invitrogen) according to the manufacturer's instructions.

Secondary antibodies employed were the following: TRITC (tetramethylrhodamine $\beta$-isothiocyanate)-conjugated donkey anti-rabbit; FITC-conjugated donkey anti-goat; and TRITCconjugated donkey anti-mouse (Jackson Immunoresearch). 

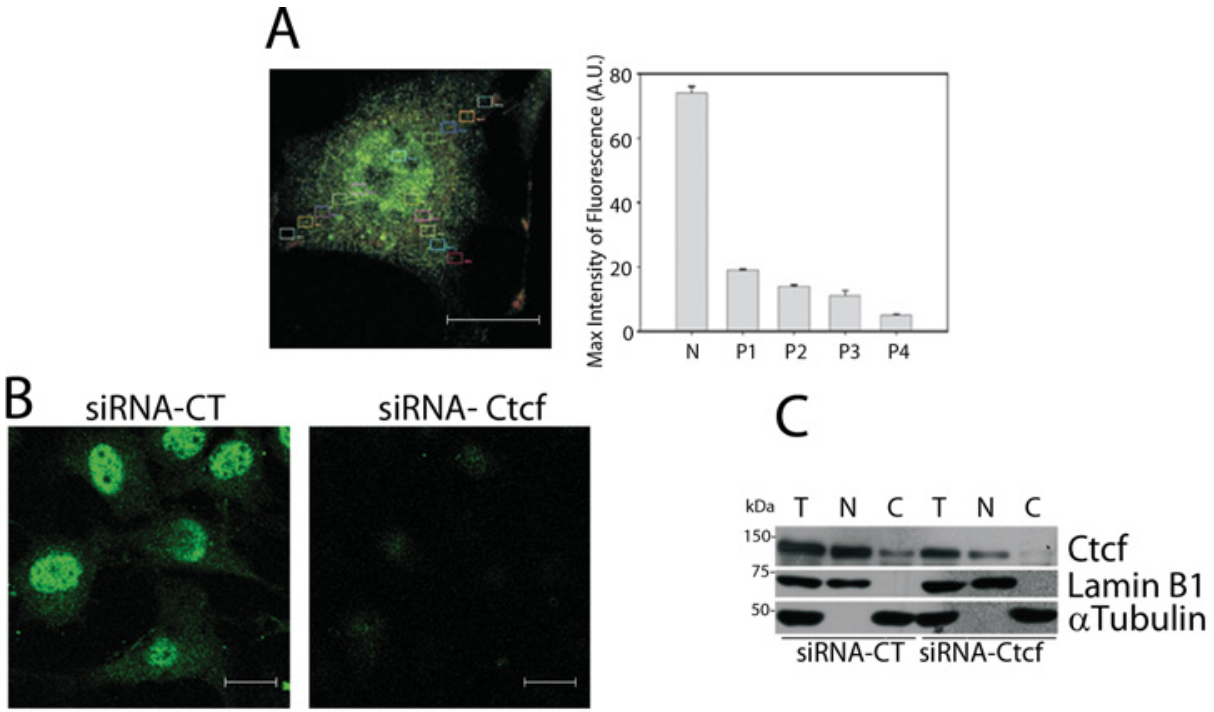

D
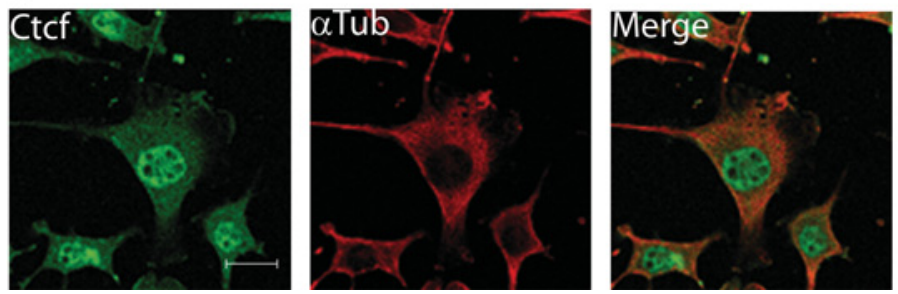

E

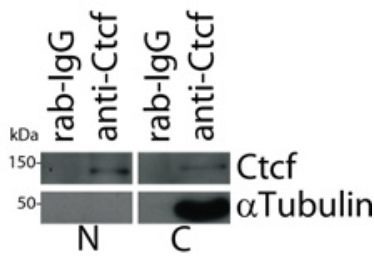

Figure 1 Analysis of cellular localization of Ctcf in L929 mouse fibroblasts

(A) CLSM of L929 cells incubated with anti-Ctcf antibodies (green). Coloured squares represent areas at different distances from the nucleus used for the quantitative analysis of fluorescence. The right-hand panel shows the histogram representing the fluorescence evaluated in the nucleus (N) and in the cytosol at different distances from the nucleus (P1, P2, P3 and P4). A.U., arbitrary units. Results are means \pm S.E.M. (B) CLSM of control (siRNA-CT) and Ctcf silenced (siRNA-Ctcf) L929 cells incubated with anti-Ctcf antibodies. (C) Western blot analysis of nuclear and cytosolic fractions isolated from control and Ctcf-silenced L929 cells performed with anti-Ctcf antibodies (T, total cell extract; N, nuclear extract; $\mathrm{C}$, cytosolic extract). Lamin B1 and $\alpha$-tubulin were used as the control for purity of nuclear and cytosolic fraction respectively. (D) CLSM of L929 cells incubated with anti-Ctcf (green) and anti- $\alpha$-tubulin (red) antibodies, the merged image is shown in the right-hand panel. (E) Ctcf immunoprecipitation experiments carried out using L929 nuclear (N) and cytosolic (C) fractions with anti-Ctcf and anti- $\alpha$-tubulin antibodies used to demonstrate fraction purity. Scale bars, $20 \mu \mathrm{m}$.

For immunolocalization, a Leica confocal microscope (Laser Scanning TCS SP2) equipped with Ar/ArKr and HeNe lasers was utilized. The images were acquired utilizing the Leica confocal software. Laser line was at $488 \mathrm{~nm}$ for FITC, $543 \mathrm{~nm}$ for TRITC and 633 for TO-PRO-3 excitation respectively. The images were scanned under a $40 \times$ oil immersion objective. In addition to the qualitative analysis of antigen distribution, a quantitative analysis was carried out using the Leica confocal software. Optical spatial series, each composed of approximately 15 optical sections with a step size of $1 \mu \mathrm{m}$, were performed. The fluorescence intensity in equivalently sized ROIs (regions of interest) was determined by the Leica confocal software [21]. Regarding the time-lapse video experiments, cells were subjected to video microscopy for $24 \mathrm{~h}$ at $37^{\circ} \mathrm{C}$.

\section{Generation of the mutant form of pcs2-Myc-PARG overexpression vector}

The catalytically inactive Myc-PARG (E757N) mutant was obtained using the QuickChange ${ }^{\circledR}$ site-directed mutagenesis method (Stratagene).The plasmid pcs2-Myc-PARG was used as a template, and the primers for mutagenesis were: Parg (E757N) forward, 5'-GCAGGACTTGTGCAAGAAAACATCCGCTTTTTAATCAA-3'; and Parg (E757N) reverse, 5'-GCGGATGTTTTCTTGCACAAGTCCTGCACTGG-3' (the mutated nucleotides are in bold). The reaction was performed using the primers at a final concentration of $200 \mathrm{nM}, 50 \mathrm{ng}$ of plasmid template, 10 units of Pfu turbo DNA polymerase (Stratagene) and $100 \mu \mathrm{M}$ dNTPs in $50 \mu \mathrm{l}$ of reaction mixture. The reaction conditions were: one step at $95^{\circ} \mathrm{C}$ for $5 \mathrm{~min} ; 15$ cycles at $95^{\circ} \mathrm{C}$ for $30 \mathrm{~s}$, $55^{\circ} \mathrm{C}$ for $1 \mathrm{~min}, 68^{\circ} \mathrm{C}$ for $1 \mathrm{~min}$, and a final step at $68^{\circ} \mathrm{C}$ for 7 min. To selectively digest template DNA, the PCR product was treated with DpnI enzyme for $2 \mathrm{~h}$ at $37^{\circ} \mathrm{C}$ and then transformed into TOP10 chemically competent Escherichia coli cells. Clones were sequenced using the primer PargMut seq 5'-GTCTGAAGTGAAGAGCATCGAT-3'.

\section{RESULTS}

\section{Cellular localization of Ctcf}

We first analysed Ctcf distribution in L929 mouse fibroblasts by CLSM (confocal laser-scanning microscopy). Although Ctcf is located mainly in the nucleoplasm, a clear signal was also observed in the cytoplasm (Figure 1A, right-hand panel). Quantitative analysis of Ctcf fluorescence in the nucleus and in the cytoplasm at different distances from the nucleus showed a decrease in signal going from the centre to cell periphery. Endogenous Ctcf was diffusely distributed throughout the nucleoplasm and it was undetectable in the nucleoli 

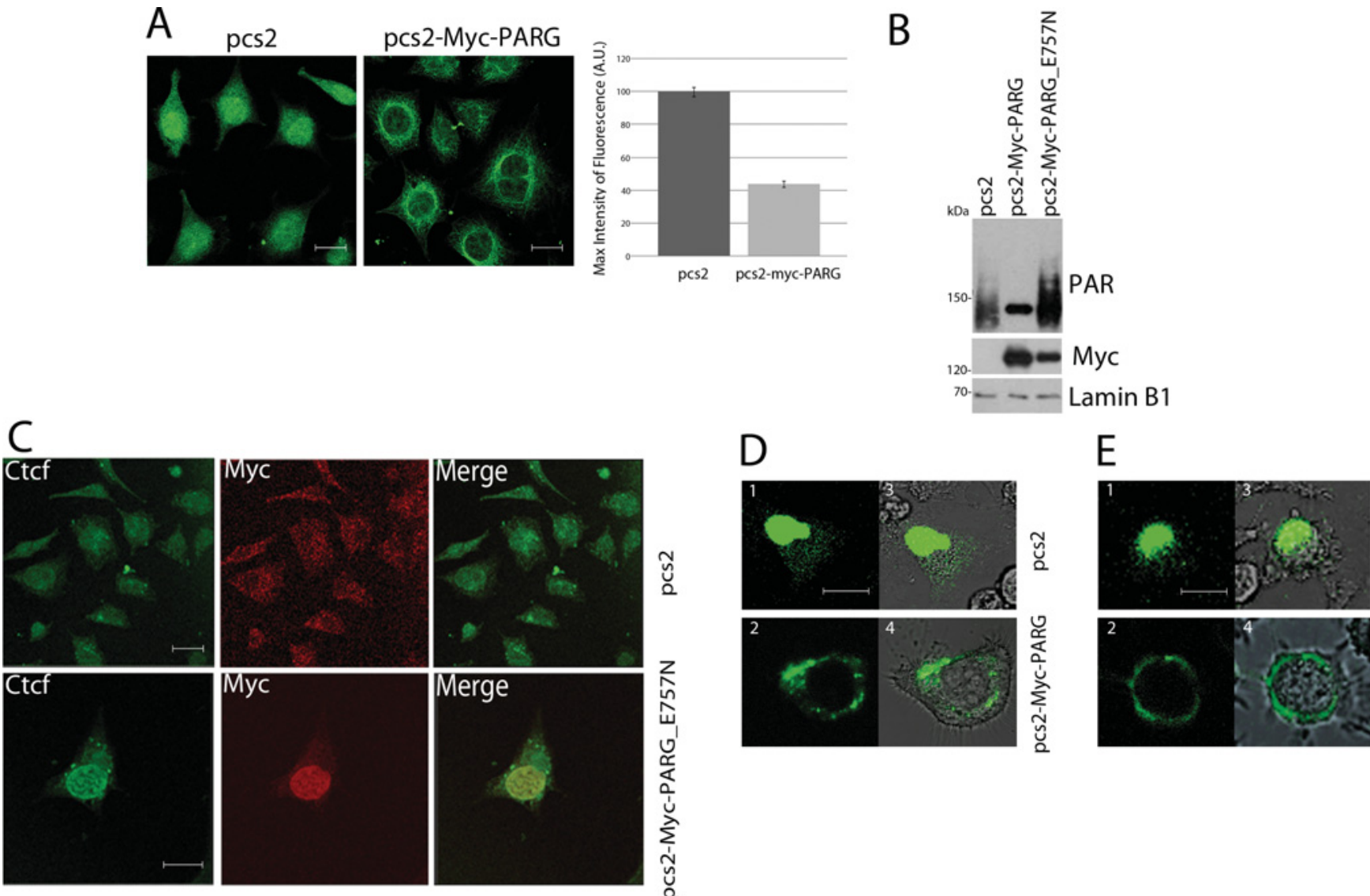

率

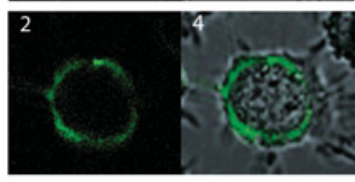

\section{Figure 2 Role of PARs in Ctcf nuclear re-localization}

(A) CLSM of L929 cells overexpressing pcs2-Myc-PARG vector and the corresponding control (pcs2) using the anti-Ctcf antibodies. The histogram presenting Ctcf fluorescence in Parg-overexpressing L929 cells relative to the fluorescence in control cells is shown on the right-hand side. Results are means \pm S.E.M. (B) Western blot analysis of L929 cells overexpressing PARG, pcs2-Myc-PARG $(E 757 \mathrm{~N})$ and the empty vector pcs2, after $72 \mathrm{~h}$ of treatment with puromycin. Analyses were performed with the anti-PAR, anti-Myc and anti-(lamin B1) (control) antibodies. (C) CLSM of L929 cells overexpressing pcs2 and pcs2-Myc-PARG (E757N) incubated with the anti-Ctcf (green) and anti-Myc (red) antibodies, the right-hand panel shows the merged image. (D) CLSM of L929 cells co-overexpressing pcs2/EGFP-CTCF wild-type ( 1 and 3 ) and pcs2-Myc-PARG/EGFP-CTCF wild-type (2 and 4) vectors. In 3 and 4, the same images are displayed in transmitted light. (E) CLSM of L929 cells co-overexpressing the pcs2/EGFP-CTCF mutant deficient for PARylation (1 and 3) and pcs2-Myc-PARG/EGFP-CTCF mutant (2 and 4) vectors. In 3 and 4, the same images are displayed in transmitted light. Scale bars, $20 \mu \mathrm{m}$.

[22] (Supplementary Figure S1 at http://www.biochemj.org/ bj/449/bj4490623add.htm). Ctcf knockdown was performed in L929 cells to verify the specificity of Ctcf staining in the cytosolic compartment. The CLSM showed a dramatic decrease in the Ctcf signal intensities both in the nucleus and in the cytoplasm (Figure 1B). In addition, Western blot experiments using total, nuclear and cytosolic cell extracts showed that the Ctcf levels decreased in all the cellular subfractions obtained from the Ctcfsilenced cells compared with controls (Figure 1C). Using lamin $\mathrm{B} 1$ as the nuclear marker and $\alpha$-tubulin as a cytosolic marker, the purity of nuclear and cytosolic fractions was confirmed (Figure 1C). The cytosolic distribution of Ctcf was further characterized by co-staining cells for anti- $\alpha$-tubulin, one of the major structural constituents of the cytoskeleton. The merged image showed that Ctcf and $\alpha$-tubulin co-localize in the cytosol of L929 cells (Figure 1D). Moreover, co-immunoprecipitation experiments confirmed that Ctcf and $\alpha$-tubulin interact in vivo (Figure 1E).

\section{PAR depletion induces Ctcf perinuclear accumulation}

To analyse whether PARylation can affect Ctcf localization, depletion of the endogenous PARs was achieved by semistable ectopic overexpression of Myc-PARG, as described previously [13]. After $72 \mathrm{~h}$ of puromycin selection, cells overexpressing Myc-PARG or the corresponding control vector (pcs2) were stained using the anti-Ctcf antibody and then subjected to CLSM. Figure 2(A) and Supplementary Figure S2(A) (at http://www.biochemj.org/bj/449/bj4490623add.htm) show that PARG overexpression leads to a net change of Ctcf distribution with reduced intranuclear staining and perinuclear accumulation. Quantitative analysis of Ctcf fluorescence recovered in the nucleus of PARG-overexpressing cells was approximately $60 \%$ less than in control cells. To confirm that the observed relocalization of Ctcf from the nucleus was due to a PAR decrease dependent on PARG activity, we transfected L929 cells with the pcs2-Myc-PARG (E757N) expression vector, which carries a mutation in the PARG catalytic site completely abolishing its enzymatic activity. Western blot analysis showed that transfection of Myc-PARG (E757N) did not affect PAR levels (Figure 2B). Accordingly, CLSM using anti-Ctcf and anti-Myc antibodies showed no relocation of Ctcf in cells overexpressing the mutant form of PARG (Figure 2C). Immunofluorescence using antiMyc antibodies showed that the PARG mutant did not show any difference from the wild-type in its nuclear localization (Figure 2C and Supplementary Figure S2A). 
A
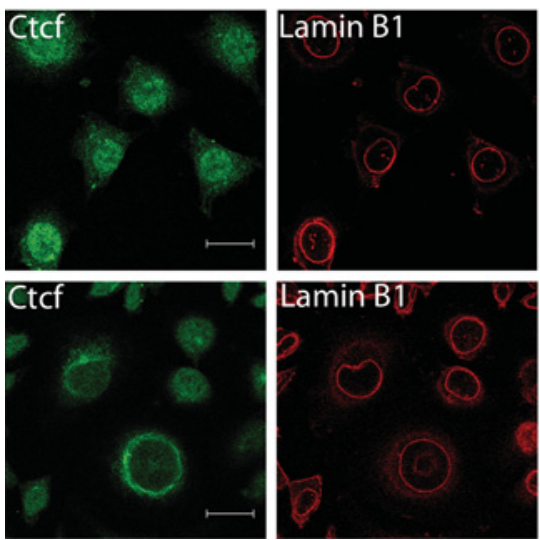

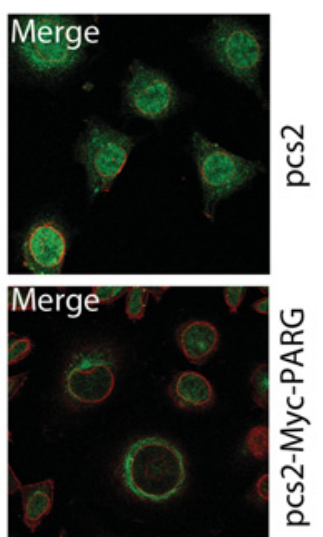

B

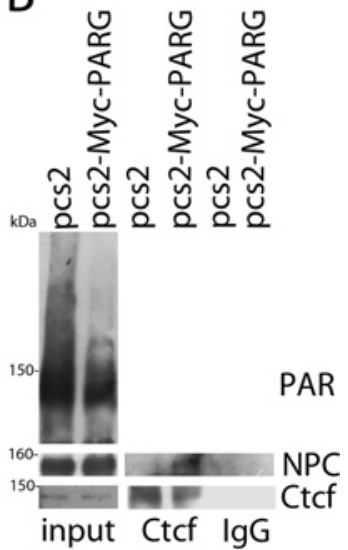

Figure 3 Ctcf interactions at the nuclear periphery

(A) CLSM of L929 cells overexpressing pcs2-Myc-PARG and the corresponding empty vector pcs2 using the anti-Ctcf (green) and anti-lamin B1 (red) antibodies. Merged immunofluorescence images are shown on the right-hand side. (B) Co-immunoprecipitation of Ctcf in L929 lysates immunoblotted using anti-NPC, anti-Ctcf and anti-PAR antibodies. Normal IgGs were used as a negative control. Scale bars, $20 \mu \mathrm{m}$.

To identify the member of the Parp family involved in the control of Ctcf localization, silencing experiments of Parp1 and Parp2, the two enzymes mainly responsible for PAR synthesis in the nucleus, were performed. Confocal microscopy analysis in Parp1-silenced cells showed a decrease of the nuclear level of Ctcf of approximately $30 \%$ (Supplementary Figure S2B). Conversely, silencing of Parp2 does not seem to affect Ctcf localization (Supplementary Figure S2C). These results were confirmed in fibroblast cells from Parp1-knockout mice (A1 cells) where the nuclear level of Ctcf was $75 \%$ less than Parp1-proficient cells (Supplementary Figure S2D).

Time-lapse experiments, carried out by co-transfecting cells with pcs2-Myc-PARG and EGFP-CTCF wild-type, confirmed that PARG overexpression affects Ctcf localization, showing that EGFP-CTCF is not able to enter the nucleus (Figure 2D freezes the sequence at $16 \mathrm{~h}$ post transfection).

To investigate whether perinuclear localization of Ctcf dependent on PAR depletion was due to a hindrance to its entering the nucleus or to its difficulty to be retained within it, we treated cells with an inhibitor of exportin CRM1 (chromosome region maintenance 1), LMB (leptomycin B). However, no difference in Ctcf perinuclear distribution was observed in cells co-tranfected with pcs2-Myc-PARG and EGFP-CTCF and treated with LMB (results not shown). Therefore, it is likely that Ctcf perinuclear accumulation was linked to the hindrance preventing Ctcf from entering the nucleus.

To assess the effect of covalent PARylation on Ctcf nuclear distribution, L929 cells were co-transfected with both pcs2-MycPARG and EGFP-CTCF mutant deficient for PARylation [16]. As shown in Figure 2(E), the mutated Ctcf is still present in the nucleus of cells in which PARylation was unaffected (Figure 2E, frames 1 and 3), whereas it relocalized at the nuclear periphery after PAR depletion (Figure 2E, frames 2 and 4), suggesting that covalent PARylation of Ctcf does not play a role in the maintenance of its nuclear localization, which is in agreement with a previous report [16].

\section{Ctcf accumulates out of the Lamin ring}

To investigate the effect of PAR depletion on Ctcf nuclear re-localization to the nuclear periphery in more detail, Myc-
PARG transfected cells were co-stained with the anti-Ctcf and anti-(lamin B1) antibodies. As shown in Figure 3(A), Ctcf accumulates out of the Lamin ring upon PARG overexpression; co-immunoprecipitation experiments revealed the absence of interaction between Ctcf and lamin B1 (results not shown). Notably, specific co-immunoprecipitation between Ctcf and proteins of the NPC was observed only in L929 cells overexpressing PARG (Figure 3B), therefore it is likely that there is an interaction between Ctcf and these proteins in vivo.

\section{PARG overexpression induces redistribution of genomic DNA at the nuclear periphery}

Previous reports demonstrated that removal of Ctcf from its DNAbinding sites leads to the silencing of some Ctcf target genes by DNA methylation $[23,24]$. Furthermore, we demonstrated that such Ctcf removal occurs following PAR depletion [18]. On the basis of this evidence we hypothesized that the depletion of nuclear Ctcf in PARG-overexpressing cells was associated with chromatin rearrangements towards repressive configurations. We analysed chromatin status in three different ways using immunofluorescence experiments: (i) studying DNA distribution by nuclear staining with TO-PRO-3 (Figure 4A); (ii) analysing 5-MeCyt levels using anti-5-MeCyt antibodies; and (iii) measuring levels of $\mathrm{H} 3 \mathrm{~K} 4 \mathrm{me} 2$ and of $\mathrm{H} 3 \mathrm{~K} 9 \mathrm{me} 3$ as marks of active/inactive chromatin regions respectively (Figure 4B).

The distribution of chromatin in pcs2-Myc-PARG and control cells was evaluated by means of confocal microscopy using the Leica confocal software to determine the fluorescence intensity of TO-PRO-3 in equivalently sized regions. This analysis was carried out considering approximately 50 optical sections recovered in different spatial series in both samples. Figure 4(A) shows a representative stack profile of ten ROIs randomly drawn along the nuclei both in control and Myc-PARG overexpressing cells. The groups of peaks of the Figures represent the fluorescence intensity detected by the confocal microscope from the beginning to the end of the sample that is in the total thickness of the examined nuclei.

The image analysis revealed that the position of the maximal amplitude of fluorescence is differently localized in the two samples. In control cells the mean of the value was located at 


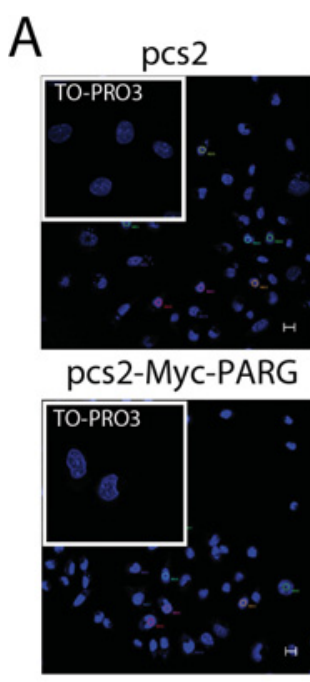

C
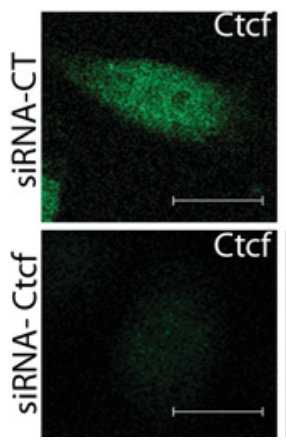
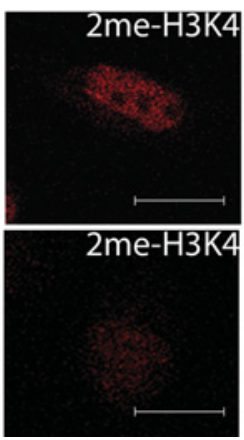
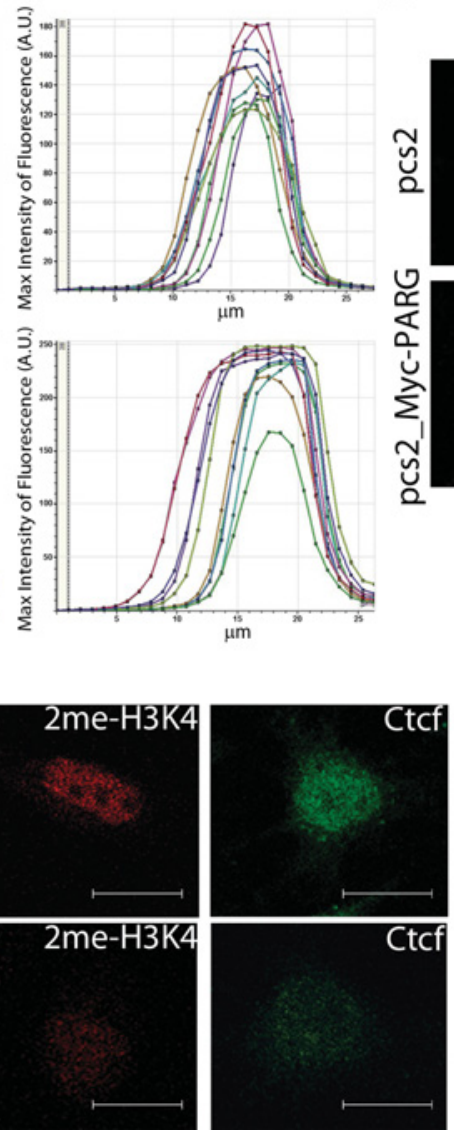

B
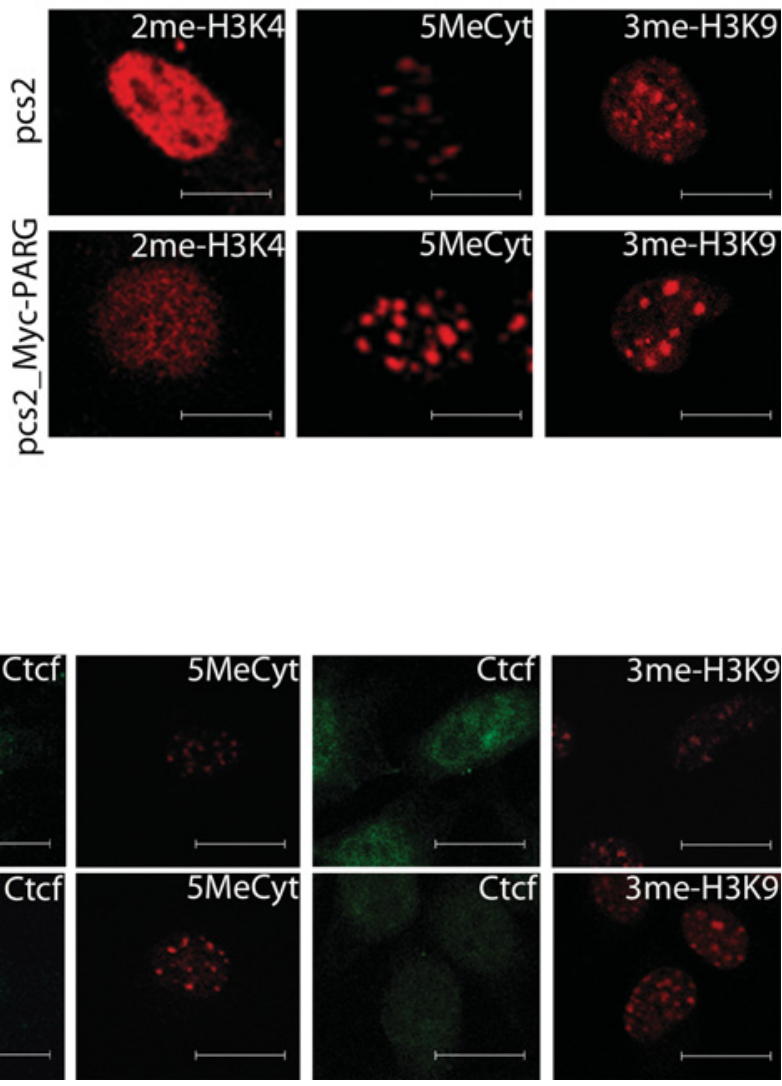

\section{Figure 4 DNA rearrangement dependent on PAR depletion}

(A) Nuclear DNA staining with T0-PRO-3 of pcs2 and pcs2-Myc-PARG overexpressing cells. The insets show enlarged details of the respective images. On the right-hand side there is a graph showing fluorescence intensity as a function of the distance (measured in $\mu \mathrm{m}$ ) of multiple peaks recovered in different nuclear areas of randomly chosen cells. (B) CLSM of L929 cells overexpressing pcs2-Myc-PARG and the relative empty vector pcs2 using anti-H3K4me2, anti-5-MeCyt and anti-H3K9me3. (C) CLSM of Ctcf-silenced L929 and the relative control cells incubated with both anti-Ctcf and anti-H3K4me2, anti-5-MeCyt and anti-H3K9me3 antibodies. Scale bars, $20 \mu \mathrm{m}$.

approximately $-10.91 \mu \mathrm{m}$ from the beginning of the sections, whereas in the Myc-PARG overexpressing cells the mean was located at approximately $-12.54 \mu \mathrm{m}$. This finding suggested that chromatin is mainly located at the periphery region of nuclei in Myc-PARG overexpressing cells.

An investigation of changes in genome methylation levels confirmed our previous data [13], showing that the level of 5MeCyt dramatically increases in PAR-depleted cells (Figure 4B). At the same time, immunofluorescence analysis using antiH3K4me2 and anti- H3K9me3 antibodies demonstrated a strong increase in condensed compared with decondensed chromatin structure in Myc-PARG overexpressing cells (Figure 4B).

Ctcf-knockdown experiments were performed to evaluate Ctcf involvement in the maintenance of the proper chromatin arrangement. Similar to the observations made under PAR depletion conditions, levels of $\mathrm{H} 3 \mathrm{~K} 4 \mathrm{me} 2$ considerably decreased, whereas levels of 5-MeCyt and $\mathrm{H} 3 \mathrm{~K} 9 \mathrm{me} 3$ increased dramatically (Figure 4C).

\section{DISCUSSION}

Genome-wide studies have indicated the presence of thousands of Ctcf-binding sites [25,26]. Ctcf, by mediating long-range chromatin interactions, does not only play an important role in the organization of chromatin architecture, but also in the regulation of gene expression. By bringing the ends of DNA loops together, Ctcf defines distinct chromatin domains; their transcriptional activity depends on whether, where and how different types of methylated histones, RNA polymerase II and p300 localize on them $[27,28]$. Ctcf acts both as an enhancer blocker and a barrier insulator [29]. In the first mechanism, it leads to gene silencing or activation, preventing or driving contacts between enhancer and promoter respectively [30,31]. As a barrier insulator, Ctcf is able to insulate chromatin regions preventing the diffusion of their active/inactive states into neighbouring chromatin regions $[30,31]$. Ctcf is multifunctional as seen in its ability to participate in diverse important biological events and this versatility can be explained by specific structural features of Ctcf. The 11 zinc fingers present in the Ctcf central domain are responsible for recognizing numerous DNA sequences [32], whereas all domains are involved in the important interactions with protein partners [33,34] and undergo post-translational modifications [35]. In particular, covalent PARylation occurs within the N-terminal domain [14]. Among the Ctcf-binding partners, the interaction of the cohesin subunit SA2 with the C-terminal tail of Ctcf is involved in important Ctcf functions [36]. This protein complex acts at the Igf2/H19 locus, where epigenetic modifications also play an important role in the control of imprinting. Ctcf generally binds unmethylated target sequences $[29,37]$ and PARP activity 
may be essential for the maintenance of correct Ctcf regulation. Previous studies have shown that the presence of PARylated Parp1 is necessary for the expression of some genes controlled by Ctcf [13-18] and that DNA methylation due to the absence of PARylation leads to the removal of Ctcf from DNA $[15,18]$.

Ctcf has been generally described as a nuclear protein. The nuclear Ctcf has been reported to associate with both chromosomal arms and centrosomes in metaphase [38], whereas its distribution is relatively uniform in interphase, with binding sites described to the periphery of the nucleolus [39] and to the proximity of the matrix [40]. In the present study we show that Ctcf is also detectable in extra-nuclear cell compartments as described previously [41]. The specificity of the cytosolic staining of Ctcf was confirmed in Ctcf-silenced cells showing a decrease of fluorescence in both nucleus and cytosol. Furthermore, the cytosolic localization of Ctcf was confirmed by specific coimmunoprecipitation experiments with $\alpha$-tubulin performed in the purified cytosolic fraction.

PAR depletion leads to a loss of the diffuse presence of Ctcf within the nucleus with an approximate $60 \%$ reduction and evident re-distribution at its periphery. Specifically, Ctcf localizes outside the lamin ring and immunoprecipitation experiments showed that it was interacting with proteins within nuclear pores only after PAR depletion. Despite the fact that PARs are needed to retain Ctcf in the nucleus, the covalent Ctcf PARylation does not affect its localization [16], indeed the Ctcf mutant deficient for PARylation [16] shows a nuclear diffuse localization similar to that of the wild-type protein. In both cases, re-localization to the nuclear periphery takes place following PAR depletion. The possibility remains that the non-covalent interactions between PARs and Ctcf play a role in the maintenance of the nuclear localization of Ctcf; indeed, it is well known that Ctcf is able to link very strongly and non-covalently with both Parp1-associated and protein-free PARs [18].

The results of the present study indicate that PARylation is pivotal for maintaining nuclear functions of Ctcf. Notably the Ctcf-null mice phenotype is lethal [42], whereas knockout of Parp1 is predominantly normal [43]. In agreement, the results of the present study show that Parg overexpression is more effective than Parp1 knockdown experiments. This indicates that the control of PARylation-mediated Ctcf nuclear localization could be only partially ascribed to Parp1, which might be replaced by another member of the PARP family in its absence.

The finding that, in the absence of PARs, Ctcf loses its intranuclear localization provides an interesting parallel with the data showing that PARylation regulates the intranuclear trafficking of important proteins such as $\mathrm{p} 53$ and $\mathrm{NF}-\kappa \mathrm{B}$ (nuclear factor $\kappa \mathrm{B}$ ) $[44,45]$. In both cases the presence of PARs on proteins prevents and blocks their interaction with the CRM1 exportin and thus their nuclear export [45].

Our results from the present study indicate that nuclear localization of Ctcf, even if it is dependent on the leavel of PAR, does not share the molecular mechanism described above. The results and the time-lapse analysis support the hypothesis that, under condition of PAR depletion, the re-localization of Ctcf to the nuclear periphery was due to its difficulty in entering the nucleus, instead of the activation of its export from the nucleus.

Altogether we have demonstrated that PAR levels regulate Ctcf cellular distribution, although it remains to be defined how decreasing levels of PAR induce Ctcf perinuclear re-localization. The nuclear export of Ctcf may be mediated by an export system different from the CRM1 that is yet to be identified. Alternatively, the import system may be affected, as suggested by our experiments showing that Ctcf can interact with NPC, but it cannot pass through the nuclear pore to enter the nucleus.
We have recently provided evidence of a close link between ADP ribosylation and intracellular trafficking [46]. Karyopherin$\beta 1 /$ importin- $\beta 1$, which plays a key role in the shuttling of proteins between the cytosol and the nucleus through the NPC, is ADP ribosylated by the ER (endoplasmic reticulum)-resident ADPribosyltransferase ARTD15 [46]. Future work will clarify the protein(s) and the mechanism(s) involved in the nuclear entry of Ctcf.

Recently, perinuclear localization of Ctcf has been observed to be dependent on ER stress in mouse medulloblastoma cell lines [47]. In this regard, the lack of nuclear PARylation could induce ER stress-dependent Ctcf cellular re-localization.

As Ctcf and PARylation co-operate in the maintenance of the unmethylated Ctcf target sequences, we verified whether and how PAR depletion or Ctcf silencing affect chromatin structure. As expected, both conditions lead to the introduction of epigenetic marks typical of condensed/inactive chromatin structure: the genome becomes more methylated [48] and we observed that $\mathrm{H} 3 \mathrm{~K} 4 \mathrm{me} 2$ is less abundant in PAR-depleted cells than in control cells, whereas the nuclear level of H3K9me3 increases. Analysis carried out to verify possible changes in DNA distribution within the nucleus also showed the rearrangement of the genome. The intensity of the fluorescence signal recovered in cells where DNA had been stained with TO-PRO-3 DNA shifts to the proximity of the nuclear periphery in PAR-depleted cells.

These results are in agreement with our previous evidence showing that defective PARylation leads to anomalous hypermethylation of CpG-rich DNA regions [20]. As Ctcf is essential for protecting certain gene domains from DNA methylation, reduced nuclear levels of Ctcf in PAR-depleted cells could expose $\mathrm{CpG}$-rich Ctcf-binding regions to aberrant hypermethylation.

A recent study highlighted a role for Ctcf in the transcriptional control of several key regulators of cell cycle control and progression, whose expression is frequently altered in tumors generally by promoter hypermethylation [18]. Notably, PARylation is necessary for preserving the methylation profile of the DMR1 upstream Igf2 [18] and for the transcriptional regulation of the tumor suppressor genes p16INK4a [15] and TP53 [49]. Therefore, we can speculate that defective PARylation by reducing the nuclear level of Ctcf may be responsible for aberrant hypermethylation and transcriptional deregulation of Ctcf target genes.

Taken together, our results with the considerable co-localization of Parp1 and Ctcf in the genome [16] reinforce the importance of the cross-talk between Ctcf and PARylation in maintaining DNA methylation patterns as well as chromatin organization.

\section{AUTHOR CONTRIBUTION}

The present study was conceived and directed by Paola Caiafa. Tiziana Guastafierro and Angela Catizone conducted the majority of the experimental work with equal contribution. Fabio Ciccarone constructed the mutant form of the pcs2-Myc-PARG vector. Roberta Calabrese performed time-lapse experiments. Michele Zampieri, Maria Giulia Bacalini, Oliviano Martella and Margherita Miccheli contributed to immunofluorescence experiments. Dawn Farrar and Elena Klenova provided the EGFP-CTCF wild-type and mutant vectors. Overall supervision of the present study was undertaken by Paola Caiafa, Mariella Di Girolamo, Anna Reale and Elena Klenova.

\section{FUNDING}

This work was supported by the International Fondo per gli Investimenti della Ricerca di Base 2006 [grant number RBIN06E9Z8_003] and by the Ministero dell'Istruzione, dell'Università e della Ricerca (Progetti di Ricerca di Interesse Nazionale 2008, P.C.), Italy. 


\section{REFERENCES}

1 Ame, J. C., Spenlehauer, C. and de Murcia, G. (2004) The PARP superfamily. BioEssays 26, 882-893

2 Bonicalzi, M. E., Haince, J. F., Droit, A. and Poirier, G. G. (2005) Regulation of poly(ADP-ribose) metabolism by poly(ADP-ribose) glycohydrolase: where and when? Cell. Mol. Life Sci. 62, 739-750

3 Naegeli, H. and Althaus, F. R. (1991) Regulation of poly(ADP-ribose) polymerase. Histone-specific adaptations of reaction products. J. Biol. Chem. 266, 10596-10601

4 Ahel, I., Ahel, D., Matsusaka, T., Clark, A. J., Pines, J., Boulton, S. J. and West, S. C. (2008) Poly(ADP-ribose)-binding zinc finger motifs in DNA repair/checkpoint proteins. Nature 451, 81-85

5 Karras, G. I., Kustatscher, G., Buhecha, H. R., Allen, M. D., Pugieux, C., Sait, F., Bycroft, M. and Ladurner, A. G. (2005) The macro domain is an ADP-ribose binding module. EMBO J. 24, 1911-1920

6 Hottiger, M. O., Hassa, P. O., Luscher, B., Schuler, H. and Koch-Nolte, F. (2010) Toward a unified nomenclature for mammalian ADP-ribosyltransferases. Trends Biochem. Sci. 35, 208-219

7 Ogino, H., Nozaki, T., Gunji, A., Maeda, M., Suzuki, H., Ohta, T., Murakami, Y., Nakagama H., Sugimura, T. and Masutani, M. (2007) Loss of Parp-1 affects gene expression profile in a genome-wide manner in ES cells and liver cells. BMC Genomics 8, 41

8 Krishnakumar, R. and Kraus, W. L. (2010) The PARP side of the nucleus: molecular actions, physiological outcomes, and clinical targets. Mol. Cell 39, 8-24

9 Krishnakumar, R. and Kraus, W. L. (2010) PARP-1 regulates chromatin structure and transcription through a KDM5B-dependent pathway. Mol. Cell 39, 736-749

10 Nusinow, D. A., Hernandez-Munoz, I., Fazzio, T. G., Shah, G. M., Kraus, W. L. and Panning, B. (2007) Poly(ADP-ribose) polymerase 1 is inhibited by a histone H2A variant, $\mathrm{MacroH} 2 \mathrm{~A}$, and contributes to silencing of the inactive $\mathrm{X}$ chromosome. J. Biol. Chem. 282, 12851-12859

11 Sala, A., La Rocca, G., Burgio, G., Kotova, E., Di Gesu, D., Collesano, M., Ingrassia, A. M., Tulin, A. V. and Corona, D. F. (2008) The nucleosome-remodeling ATPase ISWI is regulated by poly-ADP-ribosylation. PLOS Biol. 6, e252

12 Reale, A., Matteis, G. D., Galleazzi, G., Zampieri, M. and Caiafa, P. (2005) Modulation of DNMT1 activity by ADP-ribose polymers. Oncogene $\mathbf{2 4}, 13-19$

13 Zampieri, M., Passananti, C., Calabrese, R., Perilli, M., Corbi, N., De Cave, F., Guastafierro, T., Bacalini, M. G., Reale, A., Amicosante, G. et al. (2009) Parp1 localizes within the Dnmt1 promoter and protects its unmethylated state by its enzymatic activity. PLOS ONE 4, e4717

14 Yu, W., Ginjala, V., Pant, V., Chernukhin, I., Whitehead, J., Docquier, F., Farrar, D., Tavoosidana, G., Mukhopadhyay, R., Kanduri, C. et al. (2004) Poly(ADP-ribosyl)ation regulates CTCF-dependent chromatin insulation. Nat. Genet. 36, 1105-1110

15 Witcher, M. and Emerson, B. M. (2009) Epigenetic silencing of the p16(INK4a) tumor suppressor is associated with loss of CTCF binding and a chromatin boundary. Mol. Cell 34, 271-284

16 Farrar, D., Rai, S., Chernukhin, I., Jagodic, M., Ito, Y., Yammine, S., Ohlsson, R., Murrell, A. and Klenova, E. (2010) Mutational analysis of the poly(ADP-ribosyl)ation sites of the transcription factor CTCF provides an insight into the mechanism of its regulation by poly(ADP-ribosyl)ation. Mol. Cell. Biol. 30, 1199-1216

17 Nocchi, L., Tomasetti, M., Amati, M., Neuzil, J., Santarelli, L. and Saccucci, F. (2011) Thrombomodulin is silenced in malignant mesothelioma by a poly(ADP-ribose) polymerase-1-mediated epigenetic mechanism. J. Biol. Chem. 286, 19478-19488

18 Zampieri, M., Guastafierro, T., Calabrese, R., Ciccarone, F., Bacalini, M. G., Reale, A. Perilli, M., Passananti, C. and Caiafa, P. (2012) ADP-ribose polymers localized on Ctcf-Parp1-Dnmt1 complex prevent methylation of Ctcf target sites. Biochem. J. 441, 645-652

19 Guastafierro, T., Cecchinelli, B., Zampieri, M., Reale, A., Riggio, G., Sthandier, O., Zupi, G., Calabrese, L. and Caiafa, P. (2008) CCCTC-binding factor activates PARP-1 affecting DNA methylation machinery. J. Biol. Chem. 283, 21873-21880

20 Caiafa, P., Guastafierro, T. and Zampieri, M. (2008) Epigenetics: poly(ADP-ribosyl)ation of PARP-1 regulates genomic methylation patterns. FASEB J. 23, 672-678

21 Catizone, A., Ricci, G. and Galdieri, M. (2008) Hepatocyte growth factor modulates Sertoli-Sertoli tight junction dynamics. J. Cell. Physiol. 216, 253-260

22 Torrano, V., Navascues, J., Docquier, F., Zhang, R., Burke, L. J., Chernukhin, I., Farrar, D., Leon, J., Berciano, M. T., Renkawitz, R. et al. (2006) Targeting of CTCF to the nucleolus inhibits nucleolar transcription through a poly(ADP-ribosyl)ation-dependent mechanism. J. Cell Sci. 119, 1746-1759

23 Davalos-Salas, M., Furlan-Magaril, M., Gonzalez-Buendia, E., Valdes-Quezada, C., Ayala-Ortega, E. and Recillas-Targa, F. (2011) Gain of DNA methylation is enhanced in the absence of CTCF at the human retinoblastoma gene promoter. BMC Cancer 11, 232

24 De La Rosa-Velazquez, I. A., Rincon-Arano, H., Benitez-Bribiesca, L. and Recillas-Targa F. (2007) Epigenetic regulation of the human retinoblastoma tumor suppressor gene promoter by CTCF. Cancer Res. 67, 2577-2585
25 Cuddapah, S., Jothi, R., Schones, D. E., Roh, T. Y., Cui, K. and Zhao, K. (2009) Global analysis of the insulator binding protein CTCF in chromatin barrier regions reveals demarcation of active and repressive domains. Genome Res. 19, 24-32

26 Phillips, J. E. and Corces, V. G. (2009) CTCF: master weaver of the genome. Cell 137 1194-1211

27 Handoko, L., Xu, H., Li, G., Ngan, C. Y., Chew, E., Schnapp, M., Lee, C. W., Ye, C., Ping, J. L., Mulawadi, F. et al. (2011) CTCF-mediated functional chromatin interactome in pluripotent cells. Nat. Genet. 43, 630-638

28 Chaumeil, J. and Skok, J. A. (2012) The role of CTCF in regulating V(D)J recombination. Curr. Opin. Immunol. 24, 153-159

29 Bell, A. C., West, A. G. and Felsenfeld, G. (2001) Insulators and boundaries: versatile regulatory elements in the eukaryotic. Science 291, 447-450

30 Krivega, I. and Dean, A. (2012) Enhancer and promoter interactions - Iong distance calls. Curr. Opin. Genet. Dev. 22, 79-85

31 Yang, J. and Corces, V. G. (2012) Insulators, long-range interactions, and genome function. Curr. Opin. Genet. Dev. 22, 86-92

32 Ohlsson, R., Renkawitz, R. and Lobanenkov, V. (2001) CTCF is a uniquely versatile transcription regulator linked to epigenetics and disease. Trends Genet. 17, 520-527

33 El-Kady, A. and Klenova, E. (2005) Regulation of the transcription factor, CTCF, by phosphorylation with protein kinase CK2. FEBS Lett. 579, 1424-1434

34 Klenova, E. M., Chernukhin, I. V., El-Kady, A., Lee, R. E., Pugacheva, E. M., Loukinov, D. I., Goodwin, G. H., Delgado, D., Filippova, G. N., Leon, J. et al. (2001) Functional phosphorylation sites in the $\mathrm{C}$-terminal region of the multivalent multifunctional transcriptional factor CTCF. Mol. Cell. Biol. 21, 2221-2234

35 Caiafa, P. and Zlatanova, J. (2009) CCCTC-binding factor meets poly(ADP-ribose) polymerase-1. J. Cell. Physiol. 219, 265-270

36 Xiao, T., Wallace, J. and Felsenfeld, G. (2011) Specific sites in the C terminus of CTCF interact with the SA2 subunit of the cohesin complex and are required for cohesin-dependent insulation activity. Mol. Cell. Biol. 31, 2174-2183

37 Kanduri, C., Pant, V., Loukinov, D., Pugacheva, E., Qi, C. F., Wolffe, A., Ohlsson, R. and Lobanenkov, V. V. (2000) Functional association of CTCF with the insulator upstream of the $\mathrm{H} 19$ gene is parent of origin-specific and methylation-sensitive. Curr. Biol. 10 , 853-856

38 Zhang, R., Burke, L. J., Rasko, J. E., Lobanenkov, V. and Renkawitz, R. (2004) Dynamic association of the mammalian insulator protein CTCF with centrosomes and the midbody. Exp. Cell Res. 294, 86-93

39 Yusufzai, T. M., Tagami, H., Nakatani, Y. and Felsenfeld, G. (2004) CTCF tethers an insulator to subnuclear sites, suggesting shared insulator mechanisms across species. Mol. Cell 13, 291-298

40 Dunn, K. L., Zhao, H. and Davie, J. R. (2003) The insulator binding protein CTCF associates with the nuclear matrix. Exp. Cell Res. 288, 218-223

41 Docquier, F., Kita, G. X., Farrar, D., Jat, P., O'Hare, M., Chernukhin, I., Gretton, S., Mandal, A., Alldridge, L. and Klenova, E. (2009) Decreased poly(ADP-ribosyl)ation of CTCF, a transcription factor, is associated with breast cancer phenotype and cell proliferation. Clin. Cancer Res. 15, 5762-5771

42 Wan, L. B., Pan, H., Hannenhalli, S., Cheng, Y., Ma, J., Fedoriw, A., Lobanenkov, V., Latham, K. E., Schultz, R. M. and Bartolomei, M. S. (2008) Maternal depletion of CTCF reveals multiple functions during oocyte and preimplantation embryo development. Development 135, 2729-2738

43 Wang, Z. Q., Auer, B., Stingl, L., Berghammer, H., Haidacher, D., Schweiger, M. and Wagner, E. F. (1995) Mice lacking ADPRT and poly(ADP-ribosyl)ation develop normally but are susceptible to skin disease. Genes Dev. 9, 509-520

44 Kanai, M., Hanashiro, K., Kim, S. H., Hanai, S., Boulares, A. H., Miwa, M. and Fukasawa, K. (2007) Inhibition of Crm1-p53 interaction and nuclear export of p53 by poly(ADP-ribosyl)ation. Nat. Cell Biol. 9, 1175-1183

45 Zerfaoui, M., Errami, Y., Naura, A. S., Suzuki, Y., Kim, H., Ju, J., Liu, T., Hans, C. P., Kim, J. G., Abd Elmageed, Z. Y. et al. (2010) Poly(ADP-ribose) polymerase-1 is a determining factor in Crm1-mediated nuclear export and retention of $\mathrm{p} 65 \mathrm{NF}-\kappa \mathrm{B}$ upon TLR4 stimulation. J. Immunol. 185, 1894-1902

46 Di Paola, S., Micaroni, M., Di Tullio, G., Buccione, R. and Di Girolamo, M. (2012) PARP16/ARTD15 is a novel endoplasmic-reticulum-associated mono-ADP-ribosyltransferase that interacts with, and modifies karyopherin- $\beta 1$. PLoS ONE 7, e37352

47 Macaluso, M., Caracciolo, V., Rizzo, V., Sun, A., Montanari, M., Russo, G., Bellipanni, G., Khalili, K. and Giordano, A. (2012) Integrating role of T antigen, Rb2/p130, CTCF and BORIS in mediating non-canonical endoplasmic reticulum-dependent death pathways triggered by chronic ER stress in mouse medulloblastoma. Cell Cycle 11, 1841-1850

48 Caiafa, P. and Zampieri, M. (2005) DNA methylation and chromatin structure: the puzzling CpG islands. J. Cell. Biochem. 94, 257-265

49 Su, C. H., Shann, Y. J. and Hsu, M. T. (2009) p53 chromatin epigenetic domain organization and p53 transcription. Mol. Cell. Biol. 29, 93-103

Received 12 September 2012/1 November 2012; accepted 2 November 2012

Published as BJ Immediate Publication 2 November 2012, doi:10.1042/BJ20121429 
online dato

\section{SUPPLEMENTARY ONLINE DATA}

\section{ADP-ribose polymer depletion leads to nuclear Ctcf re-localization and chromatin rearrangement ${ }^{1}$}

Tiziana GUASTAFIERRO ${ }^{*} \dagger^{2}$, Angela CATIZONE $\dagger^{2}$, Roberta CALABRESE* $\dagger$, Michele ZAMPIERI ${ }^{\star} \dagger$, Oliviano MARTELLA Maria Giulia BACALINI* $\uparrow$, Anna REALE* ${ }^{\star}$, Maria DI GIROLAMO§, Margherita MICCHELI* , Dawn FARRAR\|, Elena KLENOVA $\|$, Fabio CICCARONE* $\dagger^{3}$ and Paola CAIAFA* $\dagger^{3}$

*Department of Cellular Biotechnologies and Haematology "Sapienza" University Rome, V.le Regina Elena 324, 00161 Rome, Italy, †Pasteur Institute-Fondazione Cenci Bolognetti, P.le A. Moro 5, 00185 Rome, Italy, $\neq$ Department of Anatomy, Histology, Forensic Medicine and Orthopedics, Section of Histology and Embryology, Faculty of Pharmacy and Medicine, "Sapienza" University Rome, V.le Regina Elena 324, 00161 Rome, Italy, §Consorzio Mario Negri Sud, Via Nazionale 8/A, 66030 Santa Maria Imbaro, Chieti, Italy, and ॥Department of Biological Sciences, University of Essex, Wivenhoe Park, Colchester, Essex C04 3SQ, U.K.
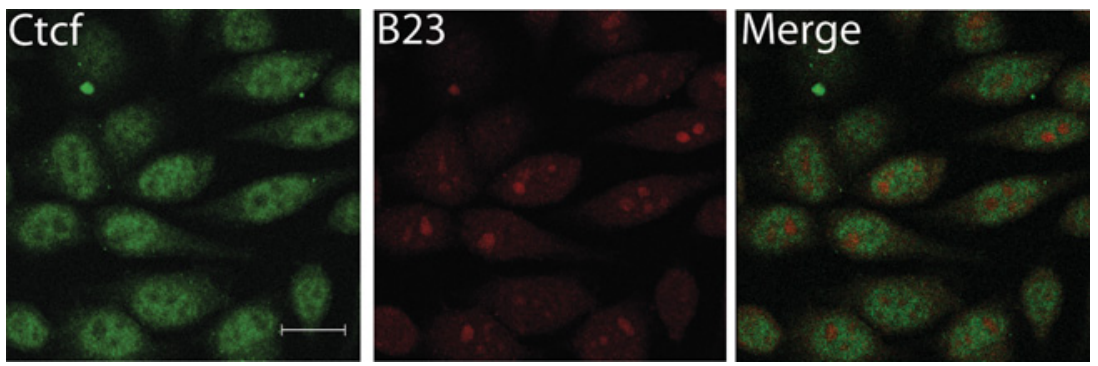

Figure S1 Ctcf is undetectable in the nucleoli

CLSM of L929 cells incubated with the anti-Ctcf (green) and anti-nucleophosmin/B23 (nucleolar marker, red) antibodies. The merged image is shown on the right-hand side. Scale bar, $20 \mu \mathrm{m}$.

1 This paper is dedicated to the memory of our wonderful colleague and friend, Dr Maria Malanga, who recently passed away. Her bright mind and her calmness in dealing with any matter will be forever engraved in our hearts.

2 These authors contributed equally to this work.

3 Correspondence may be addressed to either of these authors (email ciccarone@bce.uniroma1.it or caiafa@bce.uniroma1.it). 
A
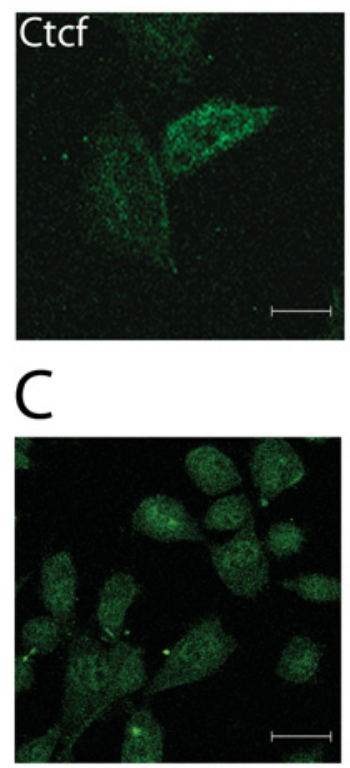

siRNA-CT
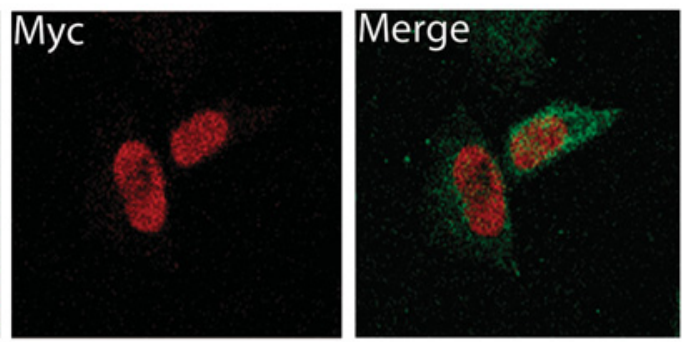

D

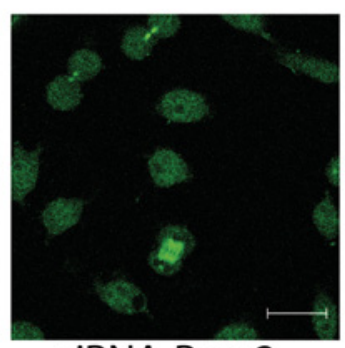

SiRNA-Parp2

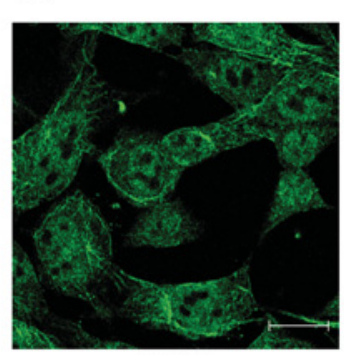

F20
B
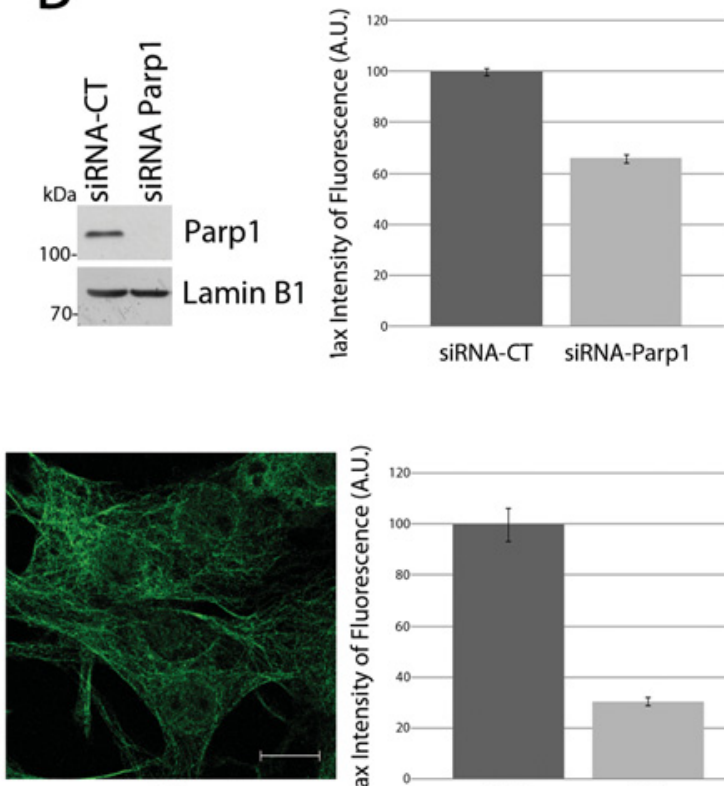

A1

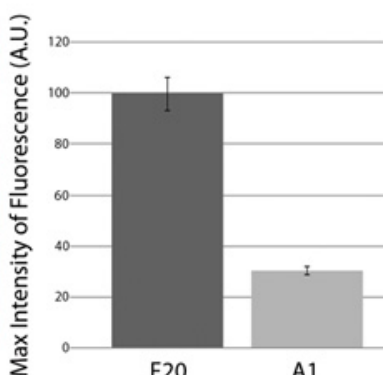

F20

A1

\section{Figure S2 Parp1 activity is responsible for Ctcf nuclear re-localization}

(A) CLSM of L929 cells transfected with pcs2-Myc-PARG vector and incubated with anti-Ctcf (green) and anti-Myc (red) antibodies. The merged image is shown on the right-hand side. (B) Western blot analysis performed using Parp1-silenced L929 (siRNA-Parp1) and corresponding control cells. Lamin B1 was used as a control. The histogram showing Ctcf fluorescence recovered in Parp1-silenced L929 and in the relative control cells is on the right-hand side. Results are means \pm S.E.M. (C) CLSM of control (siRNA-CT) and Parp2-silenced (siRNA-Parp2) L929 cells incubated with anti-Ctcf antibodies. (D) CLSM of F20 (Parp1-proficient) and A1 (Parp1-/-) cells incubated with anti-Ctcf antibodies. Scale bars, $20 \mu \mathrm{m}$. Histogram presenting the Ctcf fluorescence recovered in F20 and A1 cells is shown on the right-hand side. Results are means \pm S.E.M.

Received 12 September 2012/1 November 2012; accepted 2 November 2012

Published as BJ Immediate Publication 2 November 2012, doi:10.1042/BJ20121429 